\title{
O ZOOLÓGICO COMO RECURSO DIDÁTICO PARA EDUCAÇÃO AMBIENTAL
}

Natalia Aline Soares Artigas ${ }^{1}$

Marta Luciane Fischer²

Resumo: Os zoológicos são empregados tradicionalmente como recursos didáticos por escolas para o desenvolvimento de intervenções de educação, concomitante a sua incumbência de conservação. Questionou-se se essas demandas se retroalimentam e amplificam os esforços em prol da construção de um cidadão crítico, sustentável e ético. Objetivou-se caracterizar a Educação Ambiental por meio de revisão de literatura integrativa e transversal na interconexão entre escolas e zoológicos divulgadas no meio científico, leigo e institucional. A análise atestou incipiente divulgação científica e institucional de ações voltadas para estudantes em zoológicos, contudo identificou-se a conservação e conscientização como motivadoras das intervenções, acrescidas de limitações pedagógicas e logísticas e vulnerabilidades decorrentes da baixa sinergia das instituições e ausência de instrumentos de avaliação. Consequentemente, a abordagem a comunicação entre zoológicos e escolas necessita de fortalecimento, o que pode ser alcançado pela instauração de comitês de Bioética Ambiental fomentando a multidisciplinaridade nas intervenções educacionais.

Palavras-chave: Bioética Ambiental; Conservação da Natureza; Sustentabilidade.

\footnotetext{
${ }^{1}$ Pontifícia Universidade católica do Paraná - PPGB. E-mail: nasa.artigas@gmail.com

2Pontifícia Universidade católica do Paraná - PPGB. E-mail: marta.fischer@pucpr.br
} 


\section{Introdução}

A Educação Ambiental (EA) surgiu a menos de 50 anos no cenário científico, popular e político. Antes da década de 1950 o enfoque dos estudos com a natureza eram voltados para o conhecimento e catálogo da biodiversidade. Contudo, a industrialização, pronunciada após as Guerras mundiais, conduziu a impactos crescentes na natureza e a perspectiva de que os recursos naturais eram findáveis, levando a necessidade de instauração da EA para conter as trágicas projeções (FISCHER; FURLAN, 2018, FRANÇA; SOUZA, 2015).

O primeiro debate global sobre questões ambientais se deu em 1972 na Conferência das Nações Unidas sobre Meio Ambiente Humano, em Estocolmo, logo em seguida um encontro organizado pela UNESCO em Belgrado em 1975 congregou 65 países, sendo estabelecidas algumas normas sobre a EA. Seis anos mais tarde foi instaurada no Brasil, a Política Nacional de Meio Ambiente e o Sistema Nacional de Meio Ambiente, culminando na Conferência das Nações Unidas sobre o Meio Ambiente e Desenvolvimento em 1992 no Rio de Janeiro, em que foi determinado o Tratado de Educação Ambiental para as Sociedades Sustentáveis. Quatro anos mais tarde foi publicado os Parâmetros Curriculares Nacionais (PCNs) determinando que o tema meio ambiente deveria ser abordado em todas as disciplinas escolares. Em 1999, a Política Nacional de Educação Ambiental Brasileira (Pnea) estabeleceu a interdependência da EA com o meio natural, social e cultural (FRANÇA; SOUZA, 2015; RECIO et al., 2015). Por fim, ainda neste ano, decretou-se a Lei 9.795/99 que dispõe sobre a Educação Ambiental e enfim, a EA permeou grandes mobilizações e eventos globalmente idealizando importantes projetos voltados para conservação do meio ambiente (FISCHER; FURLAN, 2018).

Os modos de demonstrar a preocupação com a natureza são diversos acarretando diferentes paradigmas éticos. Consequentemente, a ética ambiental e a EA devem buscar sinergia com a bioética ambiental que difere da ética ambiental devido seu caráter prático e multidisciplinar (FISCHER et al., 2017a). Os debates ecológicos fizeram com que a EA fosse incentivada em ambientes educacionais e implementada por políticas públicas (FISCHER; FURLAN, 2018). $O$ art. $2^{\circ}$ da lei $9.795 / 99$ dispõe que a EA é um componente essencial e permanente da educação nacional, devendo estar presente em todos os níveis e modalidades do processo educativo, em caráter formal e nãoformal. Assim, desenvolveram-se, os Parâmetros Curriculares Nacionais (PCN) inserindo em âmbito nacional, a determinação da EA ser abarcada em todas as disciplinas e em todos os níveis de ensino (FISCHER; FURLAN, 2018), as quais devem trabalhar com temas ambientais relacionados à realidade de cada comunidade (CUNHA et al., 2013, MARIN et al., 2017).

A conexão do homem com o ambiente transpôs da "era da ecologia" própria da década de 1960 cujo foco era indicar à sociedade a necessidade da preservação do meio ambiente (OLIVEIRA; CORONA, 2008). Para Junges (2016), os impactos ambientais, juntamente com o crescimento econômico, são 
os sintomas da crise ambiental ameaçando a todas as formas de vida, demandando soluções tecnológicas e mudanças de hábitos associados com EA (CORONA, 2008; FERREIRA; BOMFIM, 2010; FRANÇA; SOUZA, 2015; JUNGES, 2016; OLIVEIRA; FRANÇA; SOUZA, 2015; RÉCIO et al., 2015). Para lacob (2013) é preciso motivar a EA para que se torne crítica e transformadora, em busca de mudanças, considerando o ensino como um projeto de pesquisa em ação. Investindo, dessa forma, no meio ambiente e para o meio ambiente. $\mathrm{Na}$ expectativa que o conhecimento promove a mudança, conclama-se pela inclusão de intervenções de EA na formação de crianças e jovens superando limitações operacionais, intelectuais e éticas (CUNHA et al., 2013; FRANÇA; SOUZA, 2015). A EA munida de concepções globais deve se adaptar as intervenções para diferentes realidades explorando recursos locais denominados espaços não formais, tais como parques, centros naturais, museus, zoológicos e aquários (HSU, 2017).

O zoológico, segundo Marin et al. (2017), se constitui de ambiente nãoformal de educação ideal para a prática ambiental devido congregar diferentes interesses e vulnerabilidades. Seu surgimento está condicionado a símbolos de poder associado primariamente à dominação egípcia, asteca e chinesa. Contudo, transpôs para função científica e didática em meados de 1820, sendo nas últimas décadas inseridas nas políticas de conservação e bem-estar animal (BEA) (COSTA, 2004; FISCHER et al., 2017b; MAZUR; CLARK, 2001; NOMURA, 2015). Ressalta-se que Broom (1991) define como BEA o estado em que os animais se encontram sob suas tentativas de superar os desafios biológicos e ambientais. Atualmente os zoológicos têm como função a conservação, pesquisa, educação, lazer e entretenimento (COSTA, 2004; NOMURA, 2015). Assim, devem promover o interesse dos visitantes que almejam um lugar para passar bons momentos em família, sem negligenciar 0 BEA e estimular o conhecimento sobre os animais através da promoção da EA (FISCHER et al., 2017b; FISCHER; FURLAN, 2018).

Os zoológicos internacionais (ZI) têm destinado investimentos na tecnologia envolvida na exibição de animais selvagens, nos programas de educação de visitantes, no desenvolvimento de melhores condições de confinamento, na contribuição para conservação por meio do desenvolvimento de técnicas de reprodução em cativeiro (TOMAS et al., 2003), diferenciando-os significativamente dos zoológicos nacionais (ZN) (MAZUR; CLARK (2001). FISCHER et al., (2017b) reforçaram que os ZI promovem ambientes voltados para elevar ao máximo os graus de BEA, substituindo confinamentos empobrecidos por recintos ativos que integram visitantes e animais, tornando mais efetivas suas práticas ambientais. No sudeste asiático a associação de zoológicos, desde 1990, composta por cerca de 90 instituições visa melhorar os ambientes, contando com uma visão ética, incluindo programas educativos (AGORAMOORTHY, 2004).

No Brasil o Museu Emílio Goeldi, no estado do Pará, fundado em 1866, destaca-se como pioneiro na exposição de animais silvestres da Amazônia (COSTA, 2004; MUSEU PARAENSE EMÍLIO GOELDI, 2018; NOMURA, 2015)

revista brasileira educação ambiental 
precedendo a criação da Sociedade de Zoológicos do Brasil (SZB) que trabalha em prol da modernização dos zoológicos (COSTA, 2004). A SZB tem como missão o desenvolvimento, melhoria e fortalecimento dos zoológicos e aquários do Brasil, auxiliando-os quanto a questões éticas que visem o BEA. Segundo a $S Z B$, no Brasil 106 zoológicos e 10 aquários registrados devem promover ações ambientais incentivando o conhecimento da população sobre a biodiversidade e como preservar os animais (COSTA, 2004).

Os zoológicos planejam ações ambientais que atendam as demandas dos visitantes e de escolas (COSTA, 2004). Muitas escolas têm procurado se adaptar para transpor da sua tradicional função de transmissora de conteúdo, orientando o estudante para o desenvolvimento de um pensamento crítico e possibilitando um bom relacionamento com a sociedade e o meio em que vivem (MARIN et al., 2017). Os zoológicos podem ser direcionados como referência para uma experiência didática prática e extracurricular. Estas instituições apresentam diversas atividades educacionais, geralmente planejadas e efetuadas por educadores ambientais. Porém, Costa (2004) ressaltou a importância de uma preparação prévia para melhor aproveitamento da visita. Os zoológicos exercem seu potencial educativo através dos programas de EA e conservação da biodiversidade (visitas orientadas, palestras e cursos) demonstrando a importância da biodiversidade (COSTA, 2004; MARIN et al., 2017), estreitando os laços, superando a mera informação (NOMURA, 2015) e, assim promovendo a conscientização (MARIN et al., 2017). Consequentemente, a avaliação da eficácia dessas intervenções vem se tornando fonte de interesse de investigação científica (NOMURA, 2015).

Partindo da evidência de que a legislação (BRASIL, 1989: Portaria $n^{\circ} 283 / 89$, art. $2^{\circ}$ ) prevê que os zoológicos devem transpassar a função de entretenimento e lazer e promover a conscientização para conservação igualmente contemplado na Lei de EA (BRASIL, 1999: Lei 9.795/99) e na Declaração Universal sobre Bioética e Direitos Humanos (ONU, 2005), o presente estudo buscou responder ao questionamento se os zoológicos têm cumprido seu papel. Assim como, se essas demandas se retroalimentam e amplificam os esforços em prol da construção de um cidadão crítico, sustentável e ético. Para tal foram testas as hipóteses: a) de existência de conexão entre EA, escolas e zoológicos; b) a divulgação das intervenções dos zoológicos é mais proeminente no meio leigo do que no científico devido as especificidades da comunicação acadêmica; c) a divulgação das intervenções de EA realizadas em ZI difere dos ZN. Desta forma, objetivou-se caracterizar Educação Ambiental por meio de uma revisão integrativa e análise transversal na interconexão entre escolas e zoológicos divulgadas no meio científico, leigo e institucional. Os dados foram analisados sob a perspectiva da Bioética Ambiental, visando mapear os benefícios, limitações e vulnerabilidades associadas à prática, a fim de promover um diálogo entre os atores dessa questão. 


\section{Metodologia}

Este estudo se constituiu de uma revisão integrativa com pesquisa transversal quantitativa e qualitativa através da categorização e mapeamento de intervenções de EA que envolvem escolas e zoológicos.

A conexão entre EA, escolas e zoológicos foi aferida por meio da análise de artigos científicos que envolvem a temática. $O$ mapeamento das intervenções de EA no ambiente escolar usando o zoológico como recurso didático se deu pela recuperação de conteúdo usando os buscadores CAPES e Google Acadêmico aplicando os termos em português e inglês: Educação Ambiental, Zoológicos e Escolas / Environmental Education, Zoos e Schools, combinados entre si. Para tal, foram recuperados os 100 primeiros resultados de cada combinação, os quais foram categorizados em práticos e teóricos. Apenas os práticos foram incluídos na amostragem para análise sob a perspectiva bioética considerando suas motivações, limitações e vulnerabilidades. A mesma metodologia foi aplicada para acessar conteúdos leigos, usando os buscadores google.com e youtube, ambos destituídos de login, a fim de minimizar o viés da amostragem.

O mapeamento institucional das intervenções de EA se deu pelo acesso de sites oficiais de ZN e ZI. Para análise de ZN utilizou-se como base a listagem de instituições divulgadas pela Sociedade de Zoológicos e Aquários do Brasil, enquanto para os ZI baseou-se na metodologia proposta por FISCHER et al. (2017b) sendo utilizados, por meio de sorteio, os zoológicos presentes nas capitais de países distribuídos nos cinco continentes. As informações foram recuperadas dos sites oficiais bem como páginas institucionais de prefeituras ou notícias veiculadas no meio digital. As informações das instituições foram categorizadas quanto: cidade, quantidade de animais, quantidade de visitantes, principais atrações, taxa de entrada, interatividades e os programas ambientais.

Os dados resultantes da categorização foram comparados em um mesmo parâmetro (programas de EA, o público alvo das ações, o objetivo da atividade, se utiliza animais e/ou métodos alternativos) e entre as variáveis (zoológicos nacionais e internacionais) por meio do teste do qui-quadrado, considerando como hipótese nula a ocorrência homogênea das categorias, a uma confiança de $95 \%$ e a um erro de $5 \%$.

\section{Resultados}

Caracterização das intervenções de Educação Ambiental na confluência
entre zoológicos e escolas no meio científico e leigo

A análise quantitativa dos textos científicos foi relativa à amostragem de 1.099 conteúdos, sendo que após a exclusão daqueles que não apresentaram conteúdo relativo a conexão dos temas, bem como os duplicados, restou $5 \%$ $(\mathrm{N}=55)$ (Tabela 1). A análise quantitativa do conteúdo popular foi relativa a uma amostragem de 600 conteúdos em textos e 300 em vídeos, sendo que após a 
exclusão daqueles que não apresentam conexão com os temas, bem como os duplicados, restou $11 \%(\mathrm{~N}=96)$, constituindo a maioria de atividades práticas envolvendo a visita de estudantes a zoológicos (Tabela 1).

Tabela 1: Frequência Relativa da categorização do conteúdo científico e popular sobre a prática da Educação Ambiental entre escolas e zoológicos.

\begin{tabular}{|c|c|c|c|}
\hline & Temas & $\begin{array}{c}\text { Científico } \\
N=55\end{array}$ & $\begin{array}{c}\text { Popular } \\
N=96\end{array}$ \\
\hline \multirow{7}{*}{$\begin{array}{l}\stackrel{0}{\pi} \\
\frac{\pi}{\pi} \\
\frac{\pi}{2}\end{array}$} & Educação Ambiental & $37,3 \%\left(^{*}\right) \mathrm{a}$ & $65,5 \%\left(^{*}\right) b$ \\
\hline & Percepção de educadores & $25,6 \%\left(^{*}\right) \mathrm{a}$ & $3,8 \% b$ \\
\hline & Percepção de estudantes & $16,3 \%$ a & $-b$ \\
\hline & Educação Ambiental e Temas específicos & $13,9 \%$ a & $15,5 \%$ a \\
\hline & Biodiversidade & $4,6 \%$ a & $1,9 \%$ a \\
\hline & Educação em espaços Não-Formais & $2,3 \% \mathrm{a}$ & $9,6 \% b$ \\
\hline & & $\chi^{2}(5)=22,1 ; P<0,0001$ & $\chi^{2}(4)=75 ; P<0,0001$ \\
\hline \multirow{6}{*}{ 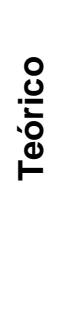 } & Educação Ambiental & $75 \%\left(^{*}\right) \mathrm{a}$ & $84 \%\left(^{*}\right) b$ \\
\hline & Educação Ambiental e Temas específicos & $16,7 \%$ a & $11 \% \mathrm{a}$ \\
\hline & Biodiversidade & $-\mathrm{a}$ & $2,5 \%$ a \\
\hline & Educação em espaços Não-Formais & $8,3 \% a$ & $2,5 \%$ a \\
\hline & & $\chi^{2}(2)=9,5 ; P<0,0001$ & $\chi^{2}(3)=88,6 ; P<0,0001$ \\
\hline & & $\begin{array}{l}\text { Científico } \\
\mathrm{N}=43\end{array}$ & $\begin{array}{l}\text { Popular } \\
\mathrm{N}=52\end{array}$ \\
\hline \multirow{11}{*}{$\begin{array}{l}\text { 응 } \\
\text { 올 } \\
\text { : }\end{array}$} & Diagnóstico & $28 \%\left(^{*}\right) \mathrm{a}$ & $4 \% b$ \\
\hline & Visitas de campo orientadas & $18,2 \%\left(^{*}\right) \mathrm{a}$ & $62 \%\left(^{*}\right) b$ \\
\hline & Teste cognitivo & $17 \%\left(^{*}\right) \mathrm{a}$ & $2 \% b$ \\
\hline & Sugestão de atividades & $14 \%\left(^{*}\right) \mathrm{a}$ & $3 \% b$ \\
\hline & Palestras & $10,6 \% \mathrm{a}$ & $10,5 \%$ a \\
\hline & $\begin{array}{l}\text { Avaliação de participantes de ações } \\
\text { ambientais }\end{array}$ & $4,5 \%$ a & $5 \%$ a \\
\hline & Aprendizagem cooperativa & $3 \% a$ & $-b$ \\
\hline & Grupo focal & $3 \% a$ & $-b$ \\
\hline & Apresentação / Divulgação & $-a$ & $11,5 \%$ b \\
\hline & \multirow[t]{2}{*}{ Educacional negativo ao zoológico } & $-a$ & $2 \% b$ \\
\hline & & $\chi^{2}(7)=28 ; P<0,0001$ & $\chi^{2}(7)=245,8 ; P<0,0001$ \\
\hline
\end{tabular}

Fonte: Elaborada pelas autoras.

* Os valores absolutos foram comparados por meio do teste do qui-quadrado tendo como hipótese nula a homogeneidade da amostra. Os valores significativamente diferentes $(P<0,05)$ resultantes da comparação entre cada variável foi acompanhado de asterisco $\left({ }^{*}\right)$. Entre as variáveis os valores distintos foram acompanhados de letras diferentes.

Os artigos apresentaram diferentes propostas de avaliação, prevalecendo os questionários. No conteúdo leigo não foram veiculados métodos de avaliação, porém foram categorizados principalmente como material informativo e educativo (Tabela 2). 
Tabela 2: Frequência Relativa da categorização do conteúdo científico e popular sobre a avaliação e tipo de abordagem de Educação Ambiental entre escolas e zoológicos.

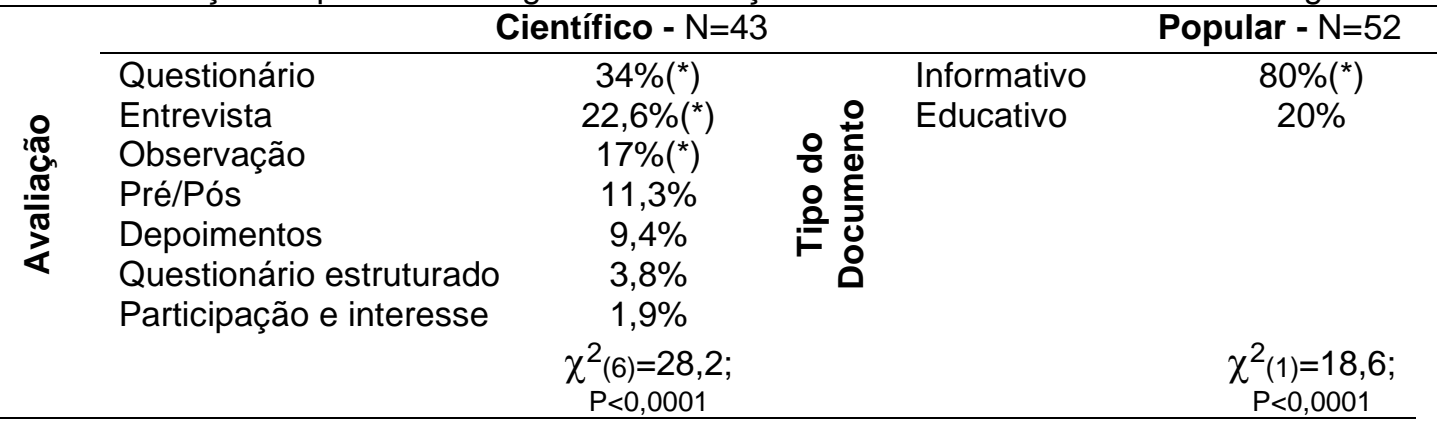

Fonte: Elaborada pelas autoras.

* Os valores absolutos foram comparados por meio do teste do qui-quadrado tendo como hipótese nula a homogeneidade da amostra. Os valores significativamente diferentes $(P<0,05)$ resultantes da comparação entre cada variável foi acompanhado de asterisco ${ }^{*}$ ).

A análise qualitativa dos artigos que relataram atividades práticas de EA resultou na identificação de três aspectos: a) motivações e afetividades relacionadas aos temas de conservação; b) abordagem ética envolvida na formação de um cidadão consciente, autônomo e crítico; c) limitações do projeto e vulnerabilidades atreladas às atividades observadas pelo próprio autor (Figura 1).

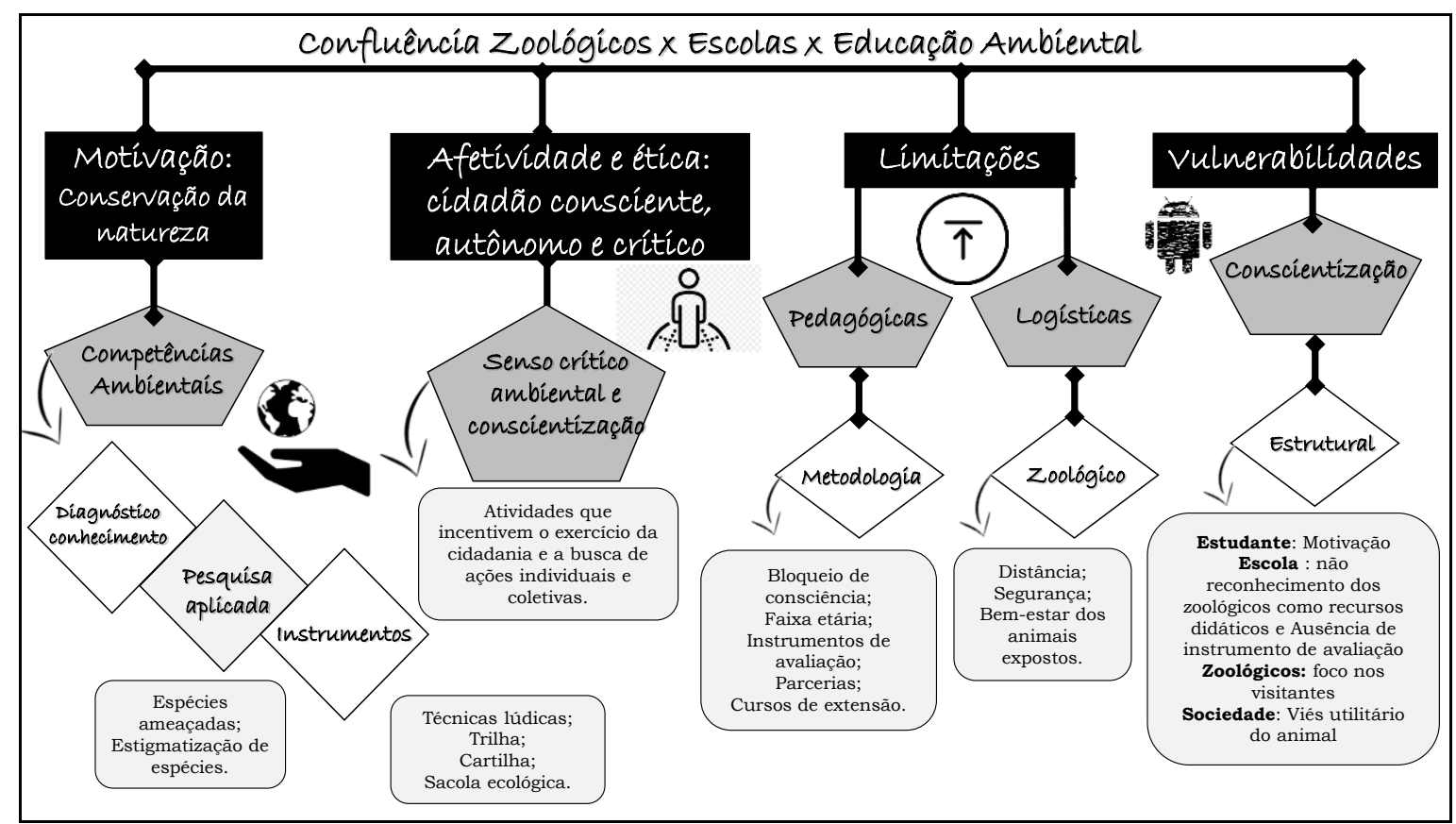

Figura 1: Síntese da análise qualitativa do conteúdo de artigos científicos a respeito de atividades práticas de Educação Ambiental em zoológicos. Fonte: Próprio autor.

Os conteúdos que abordavam questões éticas demonstraram interesse no desenvolvimento do senso crítico ambiental e conscientização (ANTQUEVES, 2015; BERNARDINI, 2012), principalmente de estudantes, por 
meio de atividades que incentivam o exercício da cidadania e a busca de ações individuais e coletivas (GARCIA; MERGULHÃO, 2001) e, por fim, sensibilizar para boas atitudes em relação à preservação das espécies (LOPES et al., 2017) (Figura 1).

As limitações apontadas incluíram tanto questões pedagógicas quanto logísticas. A identificação da incapacidade de promover a conscientização através da atividade proposta (TUNNICLIFFE, 1999; MACHADO et al., 2009; ANTQUEVES, 2015), foi relacionada com a necessidade de se utilizar uma metodologia adequada a faixa etária e perfil dos participantes (SILVA et al., 2006). A falta de parceria entre escolas, zoológicos e pesquisadores indicam a falta de atenção a essa questão, mesmo diante da demanda da promoção de EA por todos os segmentos, conclamando maior diálogo entre as partes (PEGORARO, 2003; MENDES; OLIVEIRA, 2014).

A deficiência na formação dos professores tem sido apontada como um dos problemas enfrentados, prejudicando a forma como vai ser levada a questão para a sala de aula (CHERUTTI, 2011) assim como na efetivação da interdisciplinaridade (CHAVES, 2011). A deficiência na auto regulação das ações de EA por meio de diagnósticos pré e pós intervenções podem atrasar o desenvolvimento de instrumentos efetivos. Segundo Silva (2016), a inexistência de teste inicial para possível aplicação pode acarretar dificuldades na execução (SILVA, 2016). Por outro lado, questões logísticas relacionadas com a falta de material próprio para as ações (HEPPER, 2015) e distância geográfica do zoológico (BARRETO et al., 2009) somaram-se ao apontamento de falta de segurança e o fato dos recintos serem inapropriados para abrigar animais selvagens e o questionamento ético da exposição (Figura 1).

Os textos que veicularam análise de atividades práticas revelaram a presença de vulnerabilidades em torno dos projetos desenvolvidos, destacando a utilização de animais com um viés utilitário, deixando de lado, o pensamento crítico para conservação. Neste contexto desponta os estudos de Machado et al. (2009) e Mendes e Oliveira (2014) no qual crianças realizavam enriquecimento ambiental no zoológico. Contudo pondera-se que a aplicação imprecisa pode comprometer o BEA e a proteção animal, potencializando os riscos de comprometimento de BEA de animais já vulneráveis.

A vulnerabilidade dos estudantes envolveu o fato de muitos deles não se envolveram com as atividades desinteirando-se por questões ambientais, atrasando as almejadas mudanças de pensamento. Além disso, a ausência de avaliação para análise do que foi compreendido pelos estudantes também foi apontada como uma limitação (MACHADO et al., 2009; ANTQUEVES, 2015). Concomitantemente, Silva (2016) ressaltou que a realização de intervenções sem uma ferramenta efetiva de monitoramento pode inviabilizá-las. A vulnerabilidade da escola foi atrelada aos professores que não reconhecerem a capacidade dos zoológicos ou museus como um local educativo (BARRETO et al., 2009), maximizado pela incipiência na formação ou capacitação para atividades ambientais (CHERUTTI, 2011). Cherutti (2011) contra argumentou a 
justificativa de educadores de falta de material como influenciador do insucesso das ações, pontuando que os recursos materiais não devem ser tomados como um fator determinante na aprendizagem. Concomitantemente, as instituições ao invés de atrair as escolas para o desenvolvimento de ações educativas ambientais, acabam desperdiçando essa oportunidade e não cumprem com seu papel de Educação Ambiental (CHAVES, 2011; MENDES; OLIVEIRA, 2014; HEPPER, 2015). As escolas, por sua vez não colaboram, rejeitando pesquisadores interessados nas propostas ambientais (PEGORARO, 2003). Desta forma, destaca-se a importância de parcerias entre escolas e espaços não-formais de educação. Finalmente, destaca-se a vulnerabilidade da sociedade que insere o zoológico apenas como um espaço para lazer, cuja a exposição de animais alimenta uma perspectiva antropocêntrica/utilitarista (TUNNICLIFFE, 1999; BARRETO et al., 2009) atrasando as mudanças de paradigmas para uma visão mais bio/ecocêntrica.

\section{Intervenções Ambientais oferecidas por Zoológicos Nacionais e Zoológicos Internacionais}

Dos $106 \mathrm{ZN}$ avaliados dois correspondiam a borboletários e dez a aquários. Apenas 40 zoológicos, cobravam taxa de entrada, sendo os demais gratuitos e mantidos pela prefeitura. A quantidade de visitantes anual que os zoológicos recebem foi expressiva, principalmente nos finais de semana, porém, essa informação não foi disponibilizada por todas as instituições (Tabela 3). Quatorze encontraram-se fechadas no momento da pesquisa. Entre os $50 \mathrm{ZI}$ analisados verificou-se maior quantidade de animais do que nos $\mathrm{ZN}$, sendo que a maioria cobra taxa, além de poderem cobrar por atividades diferenciadas dentro do local (Tabela 3 ).

Tabela 3: Frequência Relativa da categorização dos zoológicos analisados quanto às intervenções de Educação Ambiental.

\begin{tabular}{|c|c|c|c|c|}
\hline & & Nacional $(N=104)$ & Internacional $(\mathrm{N}=50)$ & \\
\hline \multicolumn{2}{|c|}{ Local } & $\begin{array}{l}\text { Sudeste }=54 \% \\
\text { Sul }=22 \% \\
\text { Nordeste }=9,6 \% \\
\text { Norte }=8,6 \% \\
\text { Centro Oeste = 5,7\% }\end{array}$ & $\begin{array}{l}\text { Americano }=24 \% \\
\text { Europeu }=20 \% \\
\text { Asiático }=20 \% \\
\text { Oceania }=20 \% \\
\text { Africano }=16 \%\end{array}$ & \\
\hline \multicolumn{2}{|c|}{ Taxa de entrada } & Pagos $=40(38,4 \%)$ & Pagos $=42(84 \%)$ & \\
\hline \multicolumn{2}{|c|}{ Valor da entrada } & $\begin{array}{c}\mathrm{R} \$ 20,3 \pm 27,5 \\
(\mathrm{~N}=36 ; \text { i.v. }=2,00-150,00)\end{array}$ & $\begin{aligned} & R \$ 81,1 \pm 60,5 \\
&(\mathrm{~N}=40 ; \text { i.v. }=2,76-227,9)\end{aligned}$ & \\
\hline \multicolumn{2}{|c|}{ Média anual de visitantes } & 266.238 pessoas & 6.957.522 pessoas & \\
\hline \multicolumn{2}{|c|}{ Quantidade de animais } & $\begin{array}{c}586,9 \pm 527 \\
(\mathrm{~N}=73 ; \text { i.v. }=25-3.700)\end{array}$ & \multicolumn{2}{|l|}{$\begin{array}{c}3974 \pm 5163 \\
(\mathrm{~N}=43 ; \text { i.v. }=125 \text { e } 20.219)\end{array}$} \\
\hline 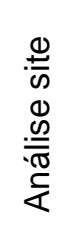 & $\begin{array}{l}\text { Imagens } \\
\text { Vídeos } \\
\text { História } \\
\text { Animais } \\
\text { Notícias } \\
\text { Publicações } \\
\end{array}$ & $\begin{array}{l}N=70 \\
N=31 \\
N=55 \\
N=57 \\
N=63 \\
N=17\end{array}$ & $\begin{array}{l}N=45 \\
N=26 \\
N=42 \\
N=44 \\
N=42 \\
N=20\end{array}$ & \\
\hline \multicolumn{4}{|c|}{ Fonte: Elaborada pelos autores. } & $\begin{array}{l}\text { de } \\
\text { educação } \\
\text { ambiental } \\
227\end{array}$ \\
\hline
\end{tabular}


Tabela 4: Frequência relativa da categorização das ações desenvolvidas nos zoológicos nacionais e internacionais.

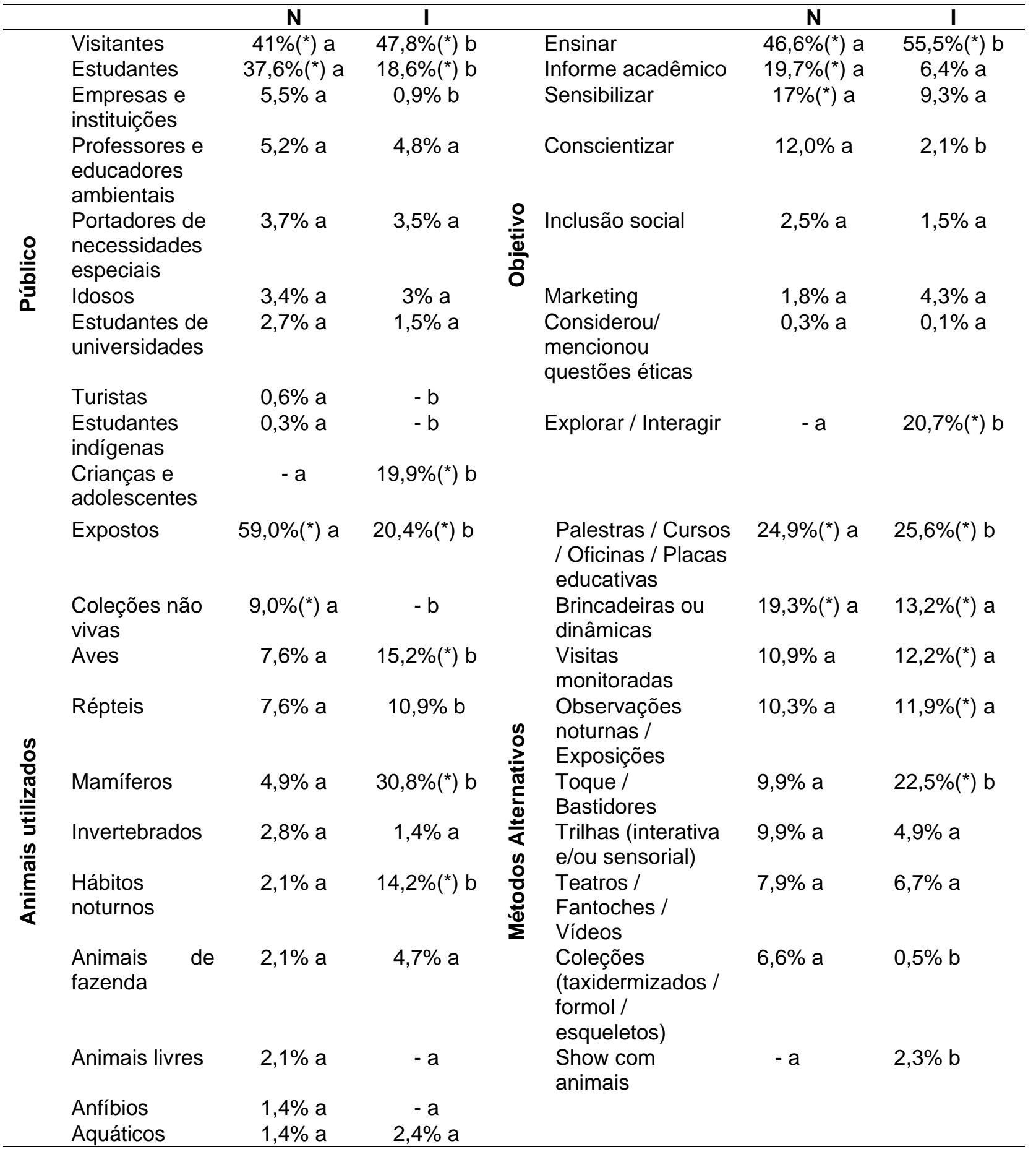

Fonte: Elaborada pelos autores.

* Os valores absolutos foram comparados por meio do teste do qui-quadrado tendo como hipótese nula a homogeneidade da amostra. Os valores significativamente diferentes $(P<0,05)$ resultantes da comparação entre cada variável foi acompanhado de asterisco $\left({ }^{*}\right)$ e entre as variáveis os valores distintos foram acompanhados de letras minúsculas diferentes. 
A maioria dos ZN não apresentava site próprio, ao contrário dos Zl. Os programas de EA foram mais frequentemente divulgados em $\mathrm{ZI}$, categorizados em doze programas para ZI e nove programas para ZN (Tabela 4, página anterior). Tanto nos ZN quanto nos internacionais destacaram-se a conscientização no próprio zoológico com ações de EA como palestras ou atividades didáticas e/ou visitas monitoradas como a maior incidência para chamar a atenção dos visitantes, acrescentando atividades sensitivas e de tecnologia para ZI.

\section{Discussão}

O presente estudo evidenciou que a EA desempenhada por zoológicos está presente nas escolas, porém, ainda de forma restrita. A deficiência de divulgações de intervenções de EA, mais frequentes nos veículos populares do que nos científicos, tanto da escola que usa o espaço do zoológico como recurso didático, quanto do zoológico que tem o dever de investir em conservação e educação, pode atrasar o objetivo de formação de cidadãos críticos, autônomos e protagonistas.

A relação entre a EA e as escolas que mencionam os zoológicos como campo de atividades foi incipiente, contrariando a expectativa da Lei 9.795/99 (BRASIL, 1999) que em seu artigo $13^{\circ}$ prevê a ampla participação da escola, da universidade e de organizações não-governamentais na formulação e execução de programas e atividades vinculadas à EA não-formal. As escolas devem desenvolver projetos em espaços não formais provendo novas e ricas oportunidades de aprendizado (MARIN et al., 2017). Por isso, o zoológico é um espaço apropriado para a promoção da EA, uma vez que possibilita a reflexão sobre animais, natureza e biodiversidade. Enquanto a escola se destaca como local ideal para formadores de opinião, logo precisa aproveitar esses ambientes.

Embora a conexão entre EA e zoológicos tenha sido evidente, não foi possível caracterizá-la plenamente ao relacionar com as práticas escolares. Segundo Marin et al., (2017), os zoológicos devem desenvolver ações ambientais para que seu visitante compreenda a importância do espaço não apenas como um local de lazer, mais como um ambiente propício para educação, reflexões, individuais ou coletivas e aprendizado. Costa (2004) mapeou experiências de EA realizadas em zoológicos constatando que dentre as instituições investigadas, todas realizavam ações de EA, porém, normalmente voltadas para os visitantes. A limitação da prática da EA na escola é exemplificada pela conclusão de Schmidt e Guerra (2013) que apontaram os projetos de EA desenvolvidos em espaços extraescolares, geralmente são encabeçados pelo município, ressaltando que embora zoológicos sejam utilizados para desenvolvimento de programas ambientais, ainda perdem para várias outras instituições, como os museus. Logo, os zoológicos precisam expandir seus ideais, além de desenvolver ações educativas na própria instituição, igualmente necessitam aproveitar que as 
escolas possuem pequenos multiplicadores para congregar agentes morais multiplicadores.

A análise dos dados revelou que a relação entre zoológicos e escolas ainda é estreita. As escolas normalmente não utilizam os zoológicos como recurso didático para a aplicação de ações ambientais, visto que a divulgação dessas aplicações é voltada apenas para registro do passeio. Assim, concebem como diversão e nem sempre como um complemento das atividades didáticas formais. Contudo, na defesa da importância desse sentimento positivo autores como Dewitt e Storksdieck (2008), Marshdoyle et al. (1982) e Meiers (2010) pontuaram o estímulo à afetividade como um objetivo dos professores em meios de educação não-formal, como zoológicos e museus, os quais devem somar com desenvolvimento cognitivo. Segundo os autores, essas experiências positivas se constituirão da base para atitudes futuras, principalmente em crianças, uma vez que se sentem encorajados a proteger a natureza, construindo conhecimentos como base para posturas futuras. Marshdoyle et al., (1982) e Meiers (2010) ressaltaram que as experiências fora da sala de aula, além de enriquecer a capacidade dos estudantes, auxiliam no aprendizado, seja afetivo ou cognitivo, aumentando o interesse e levando a vivência ao longo da vida. Esse processo foi denominado por Wilson (1984) de biofilia, postulando que se faz necessária a relação do ser humano com a natureza para promoção da sua saúde biopsicossocial, cuja incipiência pode levar a desordem do déficit de natureza em crianças (DRIESSNACK, 2009). Para Fischer e Furlan (2018) uma experiência vivenciada com a natureza pode desenvolver um senso de empatia e responsabilidade quanto a forma de tratar as necessidades do meio ambiente. Por isso, se faz necessário que as escolas compreendam o valor das atividades desempenhadas por zoológicos e utilizem esses locais como uma extensão da sala de aula, promovendo a completa experiência vivida, cognitiva ou afetiva e disseminação da nova consciência construída.

Ainda sobre a baixa expressividade de ações entre escolas e zoológicos identificou-se que as duas instituições apresentam limitações na aplicação da EA para os estudantes. Dentre os zoológicos pesquisados por Costa (2004) apenas um possuía projeto de visitas às escolas para trabalhar sobre questões ambientais, sendo que após as atividades era incentivado que o professor trabalhasse com temas relacionados. Nota-se que esses espaços têm se mostrado deficiente na promoção do conhecimento ambiental para a construção de uma sociedade mais sustentável. Marin et al., (2017) concordaram com o exposto ao mencionar que é preciso fortalecer a relação de escolas com zoológicos, sobretudo porque os zoológicos possuem uma maneira diferenciada de abordagem pedagógica aumentando a capacidade de percepção. Desta forma, tanto escolas como zoológicos fortalecem as demandas educativas. Martins et al., (2016) ao desenvolverem um projeto com o objetivo de fortalecer a integração entre escolas e zoológicos, através da percepção de diferentes atores envolvidos com as práticas educacionais ambientais, buscaram também inspirar outras instituições, concluindo que 
essas práticas reforçam a importância dos zoológicos como um ambiente multiplicador de ideias críticas voltadas ao meio ambiente. Para o fortalecimento dessas relações, a escola pode ter a iniciativa em buscar 0 zoológico como um local apropriado para atividades de complementação ambiental e os zoológicos igualmente almejando alargar seus objetivos de conscientização, deste modo, os dois sairão favorecidos (MARIN et al., 2017). Percebe-se a grande importância da vivência de situações reais para que estudantes compreendam sua finalidade, o passeio afetivo pode ser tão importante quanto o passeio cognitivo, visto que os dois acarretam na busca de um cidadão consciente e responsável.

Os dados do presente estudo confirmaram que a presença da escola no zoológico é mais divulgada em meios populares, contudo mais vinculada a um compartilhamento da vivência do que a divulgação de uma intervenção estruturada. Essa incipiência na contribuição para formação de conteúdo, potencialmente prejudica o fortalecimento desse segmento, pois não fornece parâmetros para que outras intervenções sejam realizadas. Sulaiman (2011) atribui a divulgação científica como uma fonte de importância educativa, mencionando auxílio na formação da opinião e desenvolvimento de estratégias educativas relacionadas aos temas ambientais. Como exemplo a autora citou a revista Carta na Escola. Contudo, muitos professores não sabem como conduzir essas atividades. Docentes pesquisados por Tozoni-Reis et al., (2013) relataram utilizar revistas consideradas "normais" para incentivar a EA e não as revistas científicas, mesmo cientes de que esses veículos não possuem um comprometimento com conhecimento escolar objetivando divulgação para público leigo, portanto insuficiente para o aprimoramento que se espera. 0 PRONEA (2018) apontou como um de seus objetivos a promoção de campanhas de EA nos meios de comunicação, assim, eles se tornarão colaboradores da dispersão de informações sobre o meio ambiente. Técnicas simples como jogos, panfletos, blogs e gibis, são exemplos de relatos sobre questões ambientais, nesses casos, os professores ao utilizá-las devem desenvolver uma postura crítica em seus alunos (TOZONI-REIS et al., 2013). A divulgação de ações de EA deve ser reformulada, ao serem desenvolvidas, é preciso priorizar o conhecimento dos estudantes. Consequentemente, os passeios escolares que relacionam a EA em zoológicos precisam ser difundidos como uma manifestação da importância do meio ambiente, principalmente para as pessoas que não participaram do evento, mas que pesquisam nos meios populares sobre a sua finalidade, contribuindo para que outros educadores avaliem o que deu certo e o que não deu certo para que possam ajustar sua intervenção.

As diferenças na quantidade e diversidade de ações realizadas em ZN e ZI, podem estar relacionadas tanto com a promoção quanto com a divulgação. Segundo Marin et al., (2017), os zoológicos pretendem promover em seus visitantes a reflexão sobre suas próprias condutas, porém, acabam não divulgando as atividades, contradizendo seus objetivos. Há muito tempo o ambientalismo busca demonstrar a importância de ações ambientais (JUNGES, 
2016), assim, os zoológicos devem implementar e divulgar suas ações em todos os veículos possíveis. Costa (2004) ressaltou a importância da eficácia da $E A$, concluindo que uma boa formação ambiental leva a continuidade de ações e o reconhecimento da natureza, partilhando experiências e conhecimento. Uma EA que amplie os valores a partir do respeito às outras formas de vida do planeta é necessária para que seja transformadora, por isso, é preciso que a aprendizagem não seja apenas momentânea, mas sim persista para que ocorram mudanças de atitudes humanas e sociais (FERREIRA; BOMFIM, 2010). Marin et al., (2017) atestaram que a ampliação da dimensão da EA melhora o conhecimento educativo e a participação do mediador, fazendo com que o visitante seja estimulado a pensar criticamente nos problemas enfrentados pela natureza. Percebe-se que mesmo diante da preocupação com o ambiente, a aproximação do ser humano com o meio natural ainda é contemporizada, porém, pode ser válida quando se pensa em formadores de opinião, sendo a divulgação de intervenções necessária para que atraia escolas e famílias.

A análise dos artigos científicos e dos sites de Zoológicos permitiram identificar vulnerabilidades potencializadas por uma EA incipientemente conduzida que atrasa a sinergia de segmentos que compartilham o mesmo valor: a construção do cidadão crítico, autônomo e protagonista em prol da proteção e conservação ambiental. Segundo Esteves (2011), embora o conceito de vulnerabilidade se consolide inicialmente, do campo dos direitos humanos atualmente está mais relacionada com a incapacidade de alguns setores de suprir a necessidade de melhorias, seja da sociedade, do meio ambiente ou de vários outros campos. Desta forma, identifica-se na confluência zoológicos/escolas vulnerabilidades atreladas aos animais, aos estudantes, aos professores e à sociedade.

A EA voltada para animais selvagens cativos não se constitui de um segmento beneficiado pelas atividades escolares ambientais. Sendo assim, se faz necessária uma atenção maior para esses animais que vivem isolados, normalmente em ambientes pobres e precários. Os animais nem sempre são temas de projetos de EA (SCHMIDT; GUERRA, 2013), são normalmente incluídos como um subtema para a conservação da natureza. Ao abordar questões éticas em zoológicos ou escolas voltados para área da EA, é indispensável despertar o que é certo e o que é errado, principalmente ao se deparar com os paradigmas antropocêntricos e utilitaristas. Por isso, é preciso elevar a sensibilização e fazer com que se tornem cidadãos conscientes, reeducando-os (FISCHER; FURLAN, 2018). Dorigo e Lamano-Ferreira (2015) concordaram ao mencionar que valores e atitudes podem ser questionadas, fazendo refletir para costumes mais sustentáveis. Esses espaços devem se adequar para que os animais sofram menos e para que o contato com os seres humanos seja mais prazeroso e a observação seja compatível com a natureza do animal. Assim, os animais não serão considerados seres vulneráveis e passarão a ser considerados como pacientes morais, tratados como iguais perante todas as formas de vida e tendo liberdade para ser ele mesmo. 
Os professores são mediadores essenciais na conexão entre a escola e zoológicos, principalmente de ciências e biologia, os quais pela sua formação detêm maior afinidade com o meio ambiente. Desta forma, considera-se o conhecimento prévio fundamental para a ligação da EA com a sala de aula. Tozoni-Reis et al., (2013) confirmaram que a função dos professores é desenvolver competências nos alunos, levando-os a se tornarem mais críticos, para que isso aconteça, relacionar a teoria com a prática. Assim, os docentes deixam de ser meros transmissores de informação para se tornarem formadores humanos. Essa capacidade crítica e reflexiva não deve ser imposta e sim desenvolvida pedagogicamente, estimulando a imaginação (JUNGES, 2016). Rodrigues e Colesanti (2008) mencionaram que professores devem analisar cuidadosamente as exposições ambientais digitais para que dessa forma os estudantes possam obter não somente o conhecimento, mas também formar o pensamento crítico para uma sociedade sustentável. Além disso, os autores confirmam ser necessários aspectos cognitivos para a atribuição de cidadãos críticos e participativos. Marin et al., (2017) dispuseram que muitos professores preferem não sair de sua zona de conforto e resistem na propagação de práticas diferenciadas, principalmente em locais diferentes ou fora da escola. Tozoni-Reis et al., (2013) atestaram que mesmo professores praticantes de EA demostraram dificuldade de compreensão dos objetivos de seus próprios projetos. Os autores comprovaram que a inserção da EA na sala de aula ainda é incipiente. Mesmo que existam diversos documentos que julgam necessárias as práticas ambientais, principalmente em escolas, ainda se demandam uma atenção, na formação de professores (RODRIGUES; COLESANTI, 2008). Na pesquisa de Costa (2004) apenas um zoológico foi referido como um centro de capacitação de professores e monitores, além de desenvolver estratégias didáticas para serem utilizadas em sala de aula. Com isso, observa-se que os zoológicos podem não estar aptos para habilitar professores a levar a importância da natureza e forma de vida dos animais. No entanto, Martins et al. (2016) contrapuseram essas ideias propondo a criação do projeto "Zooescola" que interliga professores aos zoológicos, aperfeiçoando a formação continuada dos docentes. Os autores, constataram, ainda, que o diálogo e a confiança são extremamente necessários para a formação de professores críticos e conscientes. Assim, professores que tem a oportunidade de desenvolver práticas de EA em salas de aula ou em outros ambientes, precisam estimular seus estudantes a pensar na crise ambiental e identificar os problemas que podem ser resolvidos com ações individuais. Vieiras e Tristão (2016) ressaltaram que as políticas de formação poderiam aproveitar as experiências cotidianas dos sujeitos transpondo os espaços como mero reprodutores de situações localizadas, mas sim como fontes de percepções e intervenções destituídas de limitações geográficas, físicas ou temporais, promovendo uma RA criativa e protagonista.

As práticas de uma EA criativa e sua vivência são essenciais para desenvolver o senso crítico em estudantes e na escola, além da família, que podem ser os responsáveis por expandir esse caminho de aprendizado. 
Rodrigues e Colesanti (2008) ressaltaram que já existem muitos cursos com temáticas ambientais destinados a professores, com fim de aperfeiçoamento. Porém, essa formação precisa começar na formação acadêmica. Jacomossi et al., (2014) pontuaram que, ao se desenvolver estratégias formais de EA, os universitários se interessam mais pelo campo ambiental e passam a participar mais de atividades voltadas a esse tema. Por isso, a formação consciente dos professores acarreta na reflexão-ação e no desenvolvimento de boas ações de EA crítica. Desta forma, não se pode atribuir a responsabilidade apenas aos professores. Tozoni-Reis et al., (2013) alertaram para o descaso das escolas públicas, onde os professores não possuem condições de melhorar o ensino para o seu estudante, perdem sua autonomia e são incapazes de alcançar qualidade nas salas de aula, o que em contraponto, seria essencial ao conhecimento. A educadora ambiental Mergulhão (2007), do zoológico de Sorocaba - SP, expos que se a educação fosse satisfatória não era necessário idealizar a EA. Em Portugal, a maioria dos programas de EA são aplicados em estudantes infantis, porém, o sistema de contratação de professores não é fixo e por isso, a saída do professor da escola acarreta normalmente no fim do projeto, devido ao desinteresse dos que ficam ou daquele que o substitui (SCHMIDT; GUERRA, 2013). Percebe-se, portanto, que os professores também estão vulneráveis a essas ações, indicando como dificuldades a falta de materiais apropriados, a falta de subsídio para a visita, deficiência no auxílio por parte dos governantes, dos diretores e companheiros de trabalho, afetando a todos.

A sociedade igualmente acaba por ser vulnerável uma vez que além da inacessibilidade a acessar textos científicos, não encontra no meio leigo informações consistentes. Schmidt e Guerra (2013) atestaram que os estudantes foram os mais beneficiados por programas de EA, porém, atentaram para pouca quantidade de programas que visam a sociedade como um todo (comunidade local, pais e turistas), principalmente para as comunidades mais desfavorecidas. Dorigo e Lamano-Ferreira (2015) e FISCHER et al., (2017b) verificaram que frequentadores de praças, parques urbanos e outros espaços públicos reconheceram a EA como uma das opções de atividades para serem desenvolvidas nesses locais, indicando que a esses ambientes são identificados como espaços para interação social e ampliação da afinidade com a natureza. Contudo se faz necessário promover conexão entre os espaços verdes, o que pode ser suprido pela existência de espaços deliberativos multidisciplinar de bioética ambiental, cuja orientação de visitas escolares, passeios familiares, turísticos e esportivos por meio de construção de intervenções de EA possibilite maior aproveitamento lúdico e cognitivo do ambiente. Desse modo, verifica-se que muitos zoológicos não cumprem plenamente com seu papel de levar conscientização às escolas e que essa prática precisa ser difundida, com isso, a população não é capaz de perceber a importância da construção de uma sociedade mais sustentável que pensa e se importa com outras formas de vida. 


\section{Conclusão}

O presente estudo se constitui de um panorama atual da abordagem científica e popular da interface zoológicos/escola por meio da EA não confirmando a hipótese inicial de uma incorporação dessa interconexão, porém confirmando ser a divulgação das intervenções mais apropriadas pelo segmento popular e mais pronunciadas em Zl. Esses resultados elucidam que a abordagem da EA pelos zoológicos precisa ser fortalecida, suas atividades educacionais ampliadas e pronunciada igualmente a sensibilização dos visitantes de finais de semana que devem transpor o zoológico como local de diversão, lazer para uma oportunidade de aprender sobre os animais, a natureza, a biodiversidade e a importância de cuidar do planeta.

Os zoológicos por envolverem múltiplos atores com interesses dispares congregam a vulnerabilidades associadas aos animais, educadores, estudantes e visitantes, cuja reflexão multidisciplinar em busca de mitigá-las por meio de valores comuns permite a apropriação pela bioética. A incorporação da questão pela bioética almeja a contribuição na formação de cidadãos críticos à crise ambiental, autônomos nas atitudes sustentáveis, protagonistas em ações conscientizadoras e inovadoras na incorporação da tecnologia intencionando substituir o uso dos animais. A proposta de criação de comitês de Bioética Ambiental nesses espaços, aos moldes dos comitês de ética em pesquisa ou ética hospital, pode se constituir de uma alternativa para a aproximação das escola, sociedade, comércio e órgãos governamentais como zoológicos, museus ou parques, cuja multidisciplinaridade deve incentivar a inclusão da EA para estudantes de todos os níveis e para sociedade como um todo. Pensando dessa forma, as vulnerabilidades encontradas podem ser mitigadas com a utilização de ações específicas e vivências, pois, ações educativas fazem com que o pensamento dos participantes seja modificado e passem a se preocupar com a forma de vida dos animais, incentivando um ambiente mais rico e próximo à vida da natureza e com promoção de elevados graus de BEA.

\section{Agradecimentos}

Agradeço à Fundação Araucária pela bolsa de Mestrado em Bioética concedida. E aos estagiários Henrique Trigo de Castro Junior, Beatriz Akemi Spitzenbergen e Monike Aparecida Matias de Souza pelo auxílio no desenvolvimento do projeto.

\section{Referências}

AGORAMOORTHY, G. Ethics and welfare in Southeast Asian zoos. Journal of Applied Animal Welfare Science, v. 7, n. 3, p. 189-195, 2004.

ANTQUEVES, L.M.C. A Educação Ambiental e atividades lúdicas: um incentivo a mudança de hábitos na geração de lixo. Revista Monografias Ambientais, v. 14, n. 2, p. 183-192, 2015. 
ARTIGAS, N.A.S.; FISCHER, M.L. Limitações no cativeiro quanto a promoção de bem-estar em primatas na percepção do visitante do Zoológico de Curitiba. Revista Brasileira de Educação Ambiental (RevBEA), v. 14, n. 2, p. 49-68, 2019.

BARRETO, K.F.B.; GUIMARÃES, C.R.P.; OLIVEIRA, I.S.S. O zoológico como recurso didático para a prática de Educação Ambiental. Revista entreideias: educação, cultura e sociedade, v. 14, n. 15, 2009.

BERNARDINI, C. Práticas de Educação Ambiental nas turmas do Pelotão Mirim da Brigada Militar de Agudo/RS. Revista Monografias Ambientais, v. 5, n. 5, p. 1009-1017, 2012.

BRASIL. Lei $\mathbf{n}^{\circ} 9.795$ de 27 de abril de 1999. Dispõe sobre a Educação Ambiental. Disponível em: <http://www.planalto.gov.br/ccivil 03/leis/L9795. htm>. Acesso em: 02 set. 2018.

BRASIL - MMA (Ministério do Meio Ambiente). Portaria no 283 P, 18 de maio de 1989. Brasília. IBAMA. Disponível em: <http://arsepel.com.br/pdf/federal/ 24 Portaria 283.pdf>. Acesso em: 02 set. 2018.

BROOM, D.M. Animal welfare: concepts and measurement. Journal of animal science. Reino Unido, 69, p. 4167-4175. 1991.

CHAVES, A.A.P. Avaliação dos recursos de Educação Ambiental nos espaços e escolas municipais de Curitiba. 2011. 176f. Dissertação (Mestrado em Tecnologia). Universidade Tecnológica Federal do Paraná, Curitiba, 2011.

CHERUTTI, G.; MATHIAS, M.O.; GARCIA, V.A.R. Utilização da sacola ecológica como recurso didático do Zoológico "Quinzinho de Barros" na Educação Ambiental em espaços não-formais de aprendizagem. Educação: Teoria e Prática, v. 21, n. 37, p. 189-207, jul/set., 2011.

COSTA, G.O. Educação Ambiental - experiências dos Zoológicos Brasileiros. REMEA-Revista Eletrônica do Mestrado em Educação Ambiental, v. 13, jul/dez., 2004.

CUNHA, I.V.P. et al. Avaliação da Educação Ambiental em escolas vinculadas a uma usina de cana-de-açúcar na Mata Sul de Pernambuco. Biotemas, v. 26, n. 3, p. 221-229, set. 2013.

DRIESSNACK, M. Children and nature-deficit disorder. Journal for Specialists in Pediatric Nursing, v. 14, n. 1, p. 73, 2009.

DEWITT, Jennifer; STORKSDIECK, Martin. A short review of school field trips: key findings from the past and implications for the future. Visitor studies, v. 11, n. 2, p. 181-197, 2008.

DORIGO, T;A.; LAMANO-FERREIRA, A.P.N. Contribuições da percepção ambiental de frequentadores sobre praças e parques no Brasil (2009-2013): revisão bibliográfica. Revista de Gestão Ambiental e SustentabilidadeGeAS, v. 4, n. 3, p. 31-45, set/dez., 2015. 
ESTEVES, C.J.O. Risco e vulnerabilidade socioambiental: aspectos conceituais. Caderno IPARDES. Curitiba-PR, v. 1, n. 2, p. 62-79, jul./dez. 2011.

FERREIRA, F.; BOMFIM, Z.A.C. Sustentabilidade Ambiental: visão antropocêntrica ou biocêntrica?. AmbientalMENTEsustentable. ano V, vol. 1, n०. 9-10, p. 37-51. jan./dez. 2010.

FISCHER, M.L. et al. Da ética ambiental à bioética ambiental: antecedentes, trajetórias e perspectivas. História, Ciências, Saúde - Manguinhos, Rio de Janeiro, v. 24, n. 2, p. 391-409, abr./jun. 2017a.

FISCHER, M.L.; FURLAN. Interfaces entre a Bioética Ambiental e a Educação Ambiental. In: SGANZERLA, Anor; RAULI, Patricia Maria Forte; RENK, Valquíria Elita. (Org.) Bioética ambiental. Curitiba: PUCPRess, 2018. p. 135163.

FISCHER, M.L.. et al. Os zoológicos sob a perspectiva da bioética ambiental: uma análise a partir do estudo de caso dos felídeos cativos. Revista Iberoamericana de Bioética, n. 4, p. 1-17, 2017b.

FRANÇA, J.P.; NETO, L.T.S. 0 calendário ecológico escolar: uma experiência de Educação Ambiental no Ensino Fundamental I, v. 6, ano 31, p. 390-401, nov. 2015.

GARCIA, V.A.R.; MERGULHÃO, M.C. Projeto-piloto de Educação Ambiental: avaliação do roteiro de visita orientada "zoobservador", um aliado à prática de Educação Ambiental em Zoológicos. Anais do Encontro Pesquisa em Educação Ambiental. 2001.

HEPPER, J. Learning by designing learning objects in zoo and wildlife education. International Zoo Educator's J., p. 70-71, 2015.

HSU, Y.H. Learning beyond schools: nonformal Environmental Education in Taiwan. Japanese Journal of Environmental Education, v. 26, n. 4, p. 33-38, 2017.

IACOB, M. Environmental education: policy and practice. Revista de Gestão e Avaliação Educacional, v. 2, n. 4, p. 63-71, jul/dez., 2013.

JACOMOSSI, R.R.; MORANO, R.; BARRICHELLO, A. O comportamento ambiental de estudantes de graduação: um modelo internacional de equações estruturais aplicado no contexto brasileiro. Revista de Gestão Social e Ambiental, v. 8, n. 3, p. 106, 2014.

JUNGES, J.R. What is the future of ethics teaching in the environmental sciences. International Journal of Ethics Education, v. 1, p. 127-135, 2016.

Lei n. 9.795, de 27 de abril de 1999 (1999). Dispõe sobre a Educação Ambiental. Disponível em: <http://www.planalto.gov.br/ccivil 03/leis/L9795. htm>. Acesso em: 02 set. 2018.

LOPES, I.B.; FURTADO, V.T.; SANTOS, L.A. Preservação da Biodiversidade na Educação Infantil. Anais do IV Congresso Internacional de Educação Científica e Tecnológica - IV CIECITEC. out., 2017. 
MACHADO, Ana Luiza Grohe. et al. Metodologia para a prática de Educação Ambiental através do enriquecimento ambiental nos recintos dos primatas do Zoológico Municipal de Cachoeira do Sul. In: SEMINÁRIO INTERNACIONAL DE EDUCAÇÃO, v. 14, 2009.

MARIN, Y.A.O.; CARVALHO, Y.K.; FREITAS, A.M.F. Escolas e Zoológicos: uma relação de continuidade no ensino da biologia e na Educação Ambiental. Anais do Encontro Nacional de Pesquisa em Educação em Ciências, Universidade Federal de Santa Catarina, jul., 2017.

MARSHDOYLE, E.; BOWMAN, M.L.; MULLINS, G.W. Evaluating programmatic use of a community resource: the zoo. Journal of Environmental Education, v. 13, n. 4, p. 19-26, 1982.

MARTINS, C.; RANCURA, K.G.O.; SILVA, R.L.F. Criação e consolidação de um programa de formação de professores na Fundação Parque Zoológico de São Paulo. Revista da SBEnBio, n. 9, p. 2586-2599, 2016.

MAZUR, N.A.; CLARK, T.W. Zoos and conservation: policy making and organizational challenges. Bulletin Series Yale School of Forestry and Environmental Studies, v. 105, p. 185-201, 2001.

MEIERS, N.J. Designing effective field trips at zoos and aquariums. Izea, net/education, may, 2010.

MENDES, M.; OLIVEIRA, M.M.D. Pilot project "The zoo goes to school", enriching the classroom. Scientia cum Industria, v. 2, n. 2, p. 47-51, 2014.

MERGULHÃO, C. Educação Ambiental - entrevista com Maria Cornélia Mergulhão, Instituto Humanitas UnisinoS.. Disponível em: <http://www.ihu. unisinos.br/?q=educa\%C3\%A7\%C3\%A30\%20ambiental>. Acesso em: 30 jan. 2019.

MMA (Ministério do Meio Ambiente). (2018). Portaria no 283 P, 18 de maio de 1989. Brasília. IBAMA. Disponível em: <http://arsepel.com.br/pdf/federal/24 Portaria 283.pdf>. Acesso em: 02 set. 2018.

MUSEU PARAENSE EMÍLIO GOELDI. História. Disponível em: $<$ https://www.museu-goeldi.br/assuntos/o-museu/historia-1>. Acesso em: 02 set. 2018.

NOMURA, H.A.Q. A conservação da biodiversidade em exposições de zoológicos: diálogos entre públicos e instituição. 2015. 169f. Dissertação (Mestrado no ensino de Ciências). Universidade de São Paulo, São Paulo, 2015.

OLIVEIRA, K.A.; CORONA, H.M.P. A percepção ambiental como ferramenta de propostas educativas e de políticas ambientais. Revista Científica ANAP Brasil, v. 1, n. 1, 2008.

ONU - Organização das Nações Unidas para a Educação, a Ciência e a Cultura. Declaração Universal sobre Bioética e Direitos Humanos. 2005. Disponível em: <http://bvsms.saude.gov.br/bvs/publicacoes/declaracao univ bioetica dir hum.pdf> Acesso em: 02 set. 2018. 
PEGORARO, J.L. Atividades educativas ao ar livre: um quadro a partir de escolas públicas da região de Campinas e dos usos de área úmida urbana com avifauna conspícua (Minipantanal de Paulínia-SP). 308f. Tese (Doutorado em Ciências da Engenharia Ambiental). Escola de Engenharia de São Carlos Universidade de São Paulo (USP), São Paulo, 2003.

ProNEA - Programa Nacional de Educação Ambiental. Ministério do Meio Ambiente. $2018 . \quad$ Disponível em $<$ https://www.mma.gov.br/publicacoes/educacao-ambiental/category/98pronea.html?download=1580:programa-nacional-de-educa\%C3\%A7\%C3\% A3o-ambiental-5\%C2\%AA-edi\%C3\%A7\%C3\%A30>. cesso em: 17 jun. 2019.

RECIO, M.A.L et al. Educacão ambiental e implementação de políticas públicas: a experiência em Araranguá/SC. Revista Políticas Públicas \& Cidades, v. 3, n. 2, p. 100-119, mai/ago., 2015.

RODRIGUES, G.S.S.C.; COLESANTI, M.T.M. Educação Ambiental e as novas tecnologias de informação e comunicação. Revista Sociedade \& Natureza, v. 20, n. 1, p. 51-66, 2008.

SCHMIDT, L.; GUERRA, J. Do ambiente ao desenvolvimento sustentável: contextos e protagonistas da Educação Ambiental em Portugal. Revista Lusófona de Educação, n. 25, p. 193-211, 2013.

SILVA, F.B. et al. Educação Ambiental: interação no campus universitário através de trilha ecológica. REMEA-Revista Eletrônica do Mestrado em Educação Ambiental, v. 17, jul/dez., 2006.

SILVA, R.L.F. Criação e consolidação de um programa de formação de professores na Fundação Parque Zoológico de São Paulo. Anais do VI Encontro Nacional De Ensino De Biologia, 2016.

SULAIMAN, S.N. Educação Ambiental, sustentabilidade e ciência: o papel da mídia na difusão de conhecimentos científicos. Ciência \& Educação, v. 17, n. 3, p. 645-662, 2011.

TOMAS, S.R.; CROMPTON, J.L.; SCOTT, D. Assessing service quality and benefits sought among zoological park visitors. Journal of Park \& Recreation Administration, v. 21, n. 2, p. 105-124, 2003.

TOZONI-REIS, M.F.C. et al. A inserção da Educação Ambiental na Educação Básica: que fontes de informação os professores utilizam para sua formação?. Ciência \& Educação, Bauru, v. 19, n. 2, p. 359-377, 2013.

TUNNICLIFFE, S.D. Zoos as centres of conservation education for primary school pupils. In: Proceedings of the 9th Symposium of the International Organization for Science and Technology (IOSTE). 1999. p. 688-695.

VIEIRAS, R.R.; TRISTÃO, M. A Educação Ambiental no cotidiano escolar: problematizando os espaçostempos de formação como processos de criação. Educação (UFSM), v. 1, n. 1, p. 159-170, 2016.

WILSON, E.O. Biophilia. Cambridge: Harvard University Press, 1984. 